\title{
Comparison of general and aesthetic effects between flapless and flap techniques in dental implantation: a meta-analysis of randomized controlled trials
}

\author{
Xiaomeng Gao, Siyu Qin, He Cai ${ }^{*}$ and Qianbing Wan ${ }^{*}$ (D)
}

\begin{abstract}
Background: Information about the aesthetic effects of flapless in implant surgeries is scant. Differences of the survival rate (SR) and crestal bone loss (CBL) between the two techniques were also controversial. Thus, this review was aimed to compare the general and aesthetic effects of flapless and flap approaches in implant surgeries.

Materials and methods: Following the principals of PRISMA, literature databases were searched for the eligible randomized controlled trials (RCTs) comparing the clinical performances of flap and flapless techniques. After that, relevant data of selected studies were pooled and analyzed to compare SR, bleeding on probing (BOP), probing depth $(\mathrm{PD})$, visual analogue scale (VAS), papillae presentation index (PPI), keratinized mucosa (KM) width and CBL between the two techniques.

Results: Fourteen RCTs were included. No significant difference was found in $\mathrm{SR}$ (RR $=-0.01,95 \%$ confidence interval $(\mathrm{Cl})(-0.05,0.04)), \mathrm{BOP}(\mathrm{OR}=0.40,95 \% \mathrm{Cl}(0.15,1.02))$, $\mathrm{KM}$ width $(\mathrm{WMD}=-0.42,95 \% \mathrm{Cl}(-1.02,0.17))$ between two groups. Subgroup analysis revealed that the difference of CBL was insignificant in two groups (WMD $=-0.13$, $95 \% \mathrm{Cl}(-0.63,0.38)$ ). However, flap techniques would lead more peri-implant PD (WMD $=-0.37,95 \% \mathrm{Cl}(-0.51$, $-0.23)$ ). Subgroup analysis also indicated lower VAS scores in flapless group after 1 day (WMD $=-1.66,95 \% \mathrm{Cl}$ $(-2.16,-1.16))$ but comparable pain experience after 3 days ( $\mathrm{WMD}=-0.59,95 \% \mathrm{Cl}(-1.33,0.16))$. Mean difference of PPI (WMD $=0.32,95 \% \mathrm{Cl}(0.28,0.35))$ between the two groups was significant.

Conclusions: The flapless procedure showed a superiority in preserving gingival papillae, reducing postoperative pain and peri-implant PD compared to the flap procedure, while exhibiting comparable effects on SR, BOP, KW width changes and CBL. Flapless technique is more recommended th the ideal soft and hard tissue implanting sites.
\end{abstract}

Keywords: Flapless, Flap, Aesthetics, Dental implants, Meta-analysis

\section{Introduction}

Implant-supported restorations have become the primary treatments for missing teeth with great prognosis [1-3]. However, the long-term clinical performances of

\footnotetext{
*Correspondence: caihe@foxmail.com; champion@scu.edu.cn State Key Laboratory of Oral Diseases, National Clinical Research Center for Oral Diseases, Department of Prosthodontics, West China Hospital of Stomatology, Sichuan University, No. 14, Section 3, South Renmin Road, Chengdu 610041, People's Republic of China
}

dental implants could be affected by many factors, such as clinicians' experience, hard and soft tissue conditions of patients and surgery procedures.

Gaining access to the alveolar bone is an indispensable step of the implant surgical procedures. The traditional way to expose the bone was the flap technique with mucosa incision and flap elevation, which makes the surgery field more visible and allows guided bone regeneration. There are some flap surgical options 
depending on incision sites, whereas most of them would have the risks of leaving scars on the gingiva, and even disrupting vasculature. Besides, horizontal incision may also impair the normal gingival papillae form. [4]

Flapless technique is a modified way to conduct implant procedures and it did not involve horizontal or vertical incisors for immediate and delayed implant placement. [5] Usually, the flap elevation step was omitted or the entrance to bone was created by a tissue punch device, drill preparation or immediate implant placement (IIP) [6]. Flapless procedure is considered as a more noninvasive approach to alveolar bone as there is no incision to cut the blood supply from bone membranes or soft tissues. Insufficiency of blood supply may result in poor bone regeneration or integration around implants [7]. There are some drawbacks of this technique though. The lack of visibility may result in a compromised implant placement. Since the punch devices are commonly narrower than implants, possible overheating during preparation is worth noting [8].

Some experts have compared the clinical performances of the two techniques mainly focusing on the SR or success rate of implants, peri-implant marginal bone loss or KM width. Those conclusions of the existing investigations were conflicting, while most of them found comparable clinic effects with similar SR between the two techniques [9-11]. However, a study discovered that flapless technique would increase the failure risks of implants [12]. Another analysis also showed that flapless procedure was more effective in preserving bone width and height [13].

To date, the comparison of aesthetic effects between the two techniques has not been investigated systematically. Implantation in the aesthetic zoom is an elaborate and complicated procedure. Horizontal incisors between adjacent teeth may damage gingival papillae and decrease the height of papillae after crown restoration. On the other side, flapless technique would remove more keratinized mucosa which is also of great importance for implant success and aesthetics [14]15. Jungwon Lee and his colleagues have revealed that flapless ridge preservation exhibited effectiveness in preserving bone width, bone height, and KM width [13]. No consensus has been reached on the benefits of flapless or flap techniques on aesthetic outcomes, soft and hard tissue alterations after surgery so far.

Here, we conducted a meta-analysis and systematic review of the effects of flapless and flap techniques on general and aesthetic clinical performances. After searching electronic databases and screening of the eligibility of searched studies, 14 RCTs were included for further analyses. The SR, BOP, PD, VAS, PPI, KM width and CBL were analyzed systematically to assess the general and aesthetic effects.

\section{Materials and methods}

The current study was conducted following the principles of Preferred Reporting Items for Systematic Reviews and Meta-analyses (PRISMA) guidelines [16]. A detailed protocol was developed and registered in advance in the PROSPERO (http://www.crd.york.ac.uk/PROSPERO/) (registration number: CRD4202019721).

Participants-Interventions-Comparisons-OutcomesStudy Design (PICOS) Question.

Participants: systematically healthy patients with loss of teeth in need of implant placement or participants in need of immediate implant placement (IIP).

Interventions: application of flapless techniques.

Comparisons: application of flap techniques.

Outcomes: general clinical outcomes like SR, BOP, peri-implant PD, and VAS; and aesthetic outcomes like PPI, KM width, and CBL.

Study design: RCTs only.

Thus, the study was designed to address the question "among patients treated with a flapless approach compared with flap implant placement, how did general and aesthetic clinical performances differ?".

\section{Eligibility criteria}

According to the PICOS question, the studies satisfied the following inclusion and exclusion criteria were included in the present review.

Inclusion criteria:

(i) Studies with patients in need of implants placement. Patients have no systematic diseases, or the women in post menopause period.

(ii) The studies should include flap and flapless techniques and compare at least one general or aesthetic outcome.

(iii) Each study should contained at least 10 patients with minimal follow-up of 3 months.

(iv) Randomized controlled clinical trials are included only.

Only RCTs were included in our research as to guarantee the high-quality outcomes to draw a convincing conclusion. Besides, any studies including the animals or the cadaver specimens were excluded. The duplicated studies, letters, case reports, case series and reviews have been excluded.

\section{Search strategies and study selection}

PubMed, Web of Science, Cochrane Library were searched for the eligible researches by two independent authors (X G and S Q) until 1st August, 2020. Key words 
used were as follows: "(((flapless and open flap surgery) OR (flap and full thickness and dental implant)) OR (flap and flapless and dental implant)) OR (flapless and flap and dental implant)". For "grey" literature, the ClinicalTrials.gov (ClinicalTrials.gov) and the International Clinical Trials Registry Platform (https://www.who.int/clinicaltrials-registry-platform) were searched for unpublished clinical studies or registries.

Firstly, the titles and abstracts of the eligible studies were imported to EndNote X8 (Thomson ResearchSoft, Standford, US) and screened according to the inclusion and exclusion criteria above. For the incomplete information in the titles or the abstract and the possible literatures qualified for the criteria, the full texts of articles were obtained. A third author $(\mathrm{H} \mathrm{C})$ was included in the process when disagreement arose and a consensus was made after discussion.

\section{Data extraction}

A standard data extraction sheet was created by digging the information of each qualified article. Detailed data of each article pertaining to author names, year, sample size, follow-up time, outcomes, loss of follow-up, etc., were listed.

\section{Quality assessments of included studies}

The risk of bias within each included RCT were graded by two independent authors (X G and S Q) based on the Cochrane Collaboration's tool for assessing risk of bias for RCTs. Quality assessments was evaluated as "low", "high", or "unclear" through seven aspects including random sequence generation, allocation concealment, blinding of participants and personnel, blinding of outcome assessment, incomplete outcome data, selective reporting, and other bias.

\section{General clinical measurements}

Primary outcomes included the results of SR, BOP, periimplant PD, VAS.

The survival of implants was defined as the implant remaining in situ without mobility or fractures [17]. BOP was defined as presence of bleeding on gentle probing $(0.15 \mathrm{Ncm})$ and recorded on a binary scale (presence/ absence) for each implant surface [18, 19]. Peri-implant PD was the distance measured from the mucosal margin to the bottom of the probable pocket to assess the periimplant diseases [20,21]. Pain and discomfort was also measured using a $10 \mathrm{~cm}$ VAS ranging from 0 (no pain) to 10 (worst pain imaginable) [22]. VAS data were analyzed into two subgroups ( 1 and 3 days), since the patients' subject feeling is of great importance in implant treatments.

\section{Aesthetic outcomes}

Secondly, we assessed the aesthetic outcomes including PPI, KM width and CBL. PPI was evaluated in the papillae between the implant and adjacent teeth $(0=$ no papilla, $1=$ less than half, $2=$ more than half but not complete, $3=$ complete fill, and $4=$ overfill). Three studies have compared the PPI index and one study has assessed both the mesial and distal PPI. In this case, only the mesial ones were included in the analysis as the mesial part of gingival papilla plays a vital role in the aesthetic outcomes [23]. KM width was measured from the mucogingival junction to the free gingival margin. The KM width in 3 months follow-up was included in the analysis [24]. Vertically CBL data from medial axial section of the implant were extracted, as three flapless techniques were included in our analysis. A correlation between different flapless procedures (IIP vs. punch/drilling) and the marginal bone loss was found after flapless surgeries in comparison the clinical effects of flapless with flap techniques [10]. Two subgroups, immediate and delayed implantation, were detected in the comparison of CBL between the two groups. The immediate group contained CBL results extracted after 6 months and the delayed included results at least 3 months after surgery.

\section{Synthesis of results}

The data obtained above were all analyzed through Review Manager version 5.3 (The Cochrane Collaboration, Copenhagen, Denmark).

SR and BOP were imported as dichotomous data, where the numbers of events in each group were extracted to evaluate the risk ratio (RR) and odds ratio (OR), respectively, in their $95 \% \mathrm{CI}$. The rest of the data were presented as means and standard deviations and analyzed as continuous figures to compare their weighted mean differences (WMD) and 95\% CI. The mean differences were considered significant as $P<0.05$. Considering the sample differences and heterogeneity of included studies, either a fixed or a random effects model was indicated and utilized.

\section{Assessment of publication bias}

The publication bias across studies was evaluated using the Egger's test by Stata SE release15 (StataCorp LP, College Station, TX, US) [25].

\section{Additional analysis}

Sensitivity analyses were performed to determine if the heterogeneity of the outcomes were dependent on any individual study. The Stata SE release 15 was utilized to 
investigate the impact of removing each of the selected studies.

To compare VAS scores within 3 days, qualified data were divided into " 1 day" and " 3 days" subgroups. Moreover, to evaluate the correlation of CBL using flapless or flap techniques after immediate or delayed implant surgery, studies included were stratified into "immediate" and "delayed" subgroups.

\section{Results}

\section{Study selection}

Initially, 593 studies were screened from PubMed, Web of Science, Cochrane Library and Open Grey with 168 duplicated articles and 3 articles investigating the same participants on different time. After the screening, only 14 studies satisfied the inclusion criteria and were included in the following investigation (Fig. 1) [23, $26-38]$.

\section{Study characteristics}

Detailed information of selected studies is listed in Table 1. A total of 720 implants were included in the analysis. Among the 14 included studies, two studies comprised smoking patients; nine studies included only delayed implant and four studies included only immediate implants, whereas one study included both delayed and immediate implantation with no further analyses about the effects of the implant timing on the outcomes. Twelve studies have more than one year follow-up time and the rest of them also showed at least 6-month follow-up time. Only three studies included implants in the aesthetic zone (anterior teeth and premolars). Most of the studies compared the results in two group people, with two studies designing the one-split RCTs. One study evaluated the outcomes of the flapless technique with one-piece implants and flap technique with twopiece implants. All of the three studies comparing PPI

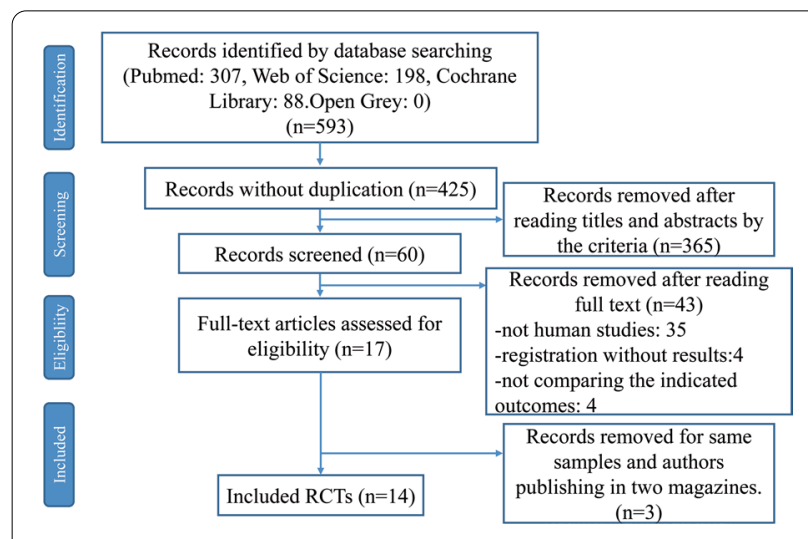

Fig. 1 Flowchart of included studies contained only delayed implant placement. Most of the studies have measured the marginal bone changes, but only the vertical bone changes were included.

\section{Risk of bias within included studies}

The risk of bias in the included RCTs was relatively high (Fig. 2). One study was at unclear risks of random sequence bias and the rest of the studies were at low risks of bias. Two studies were at low risk of allocation concealment while the rest 12 studies did not mention the allocation methods. Since the blinding of participants and personnel was hardly in practice, all of the studies were recognized as low risks of blinding of participants and personnel. Two studies had more than $10 \%$ of the patients lost to follow-up, whereas the data in the other 12 studies were comparatively complete. As for the selective reporting bias, after thorough researching, two studies have registered their trials and reported the results according to the registration. One study was at high risk of bias as it compared the flapless surgery with onepiece implant placement and flap surgery with two-piece implant placement. However, no study has high risk of bias in more than one bias item (Fig. 3).

\section{General outcomes}

The general outcomes compared the SR, BOP, PD and VAS of both techniques. No significant differences were detected between the flapless and flap approaches in SR (flapless VS flap: RR $=-0.01,95 \%$ CI $(-0.05,0.04)$, $P=0.750$ ) (Fig. 4a). Two studies were included to evaluate the BOP index. There was no significant difference between two techniques (flapless VS flap: $\mathrm{OR}=0.4,95 \%$ CI $(0.15,1.02), P=0.060)$ (Fig. 4b). As for peri- implant $\mathrm{PD}$, only results up to 3 months were included to compare the effects on soft tissue. Surprisingly, the flapless procedure resulted in a less peri-implant PD than the flap one and the difference were significant (flapless VS flap: WMD $=-0.37,95 \%$ CI $(-0.51,-0.23)$, $P<0.001$ ) (Fig. 4c). VAS between the two groups was significantly different on both day 1 and day 3 . On the first day, patients felt more pain and discomfort with worse experience after the flap procedures (flapless VS flap: WMD $=-1.66,95 \%$ CI $(-2.16,-1.16), P<0.001)$. The difference was insignificant after 3 days (flapless VS flap: $\mathrm{WMD}=-0.59,95 \% \mathrm{CI}(-1.33,0.16), P=0.120)$. And the difference was still very significant overall (flapless VS flap: WMD $=-1.32,95 \%$ CI $(-1.92,0.73), P<0.001)$ (Fig. 4d).

\section{Aesthetic outcomes}

Aesthetic outcomes put emphasis on the peri-implant soft and hard tissues. Only three studies have evaluated PPI. The flapless technique lead more gingival 


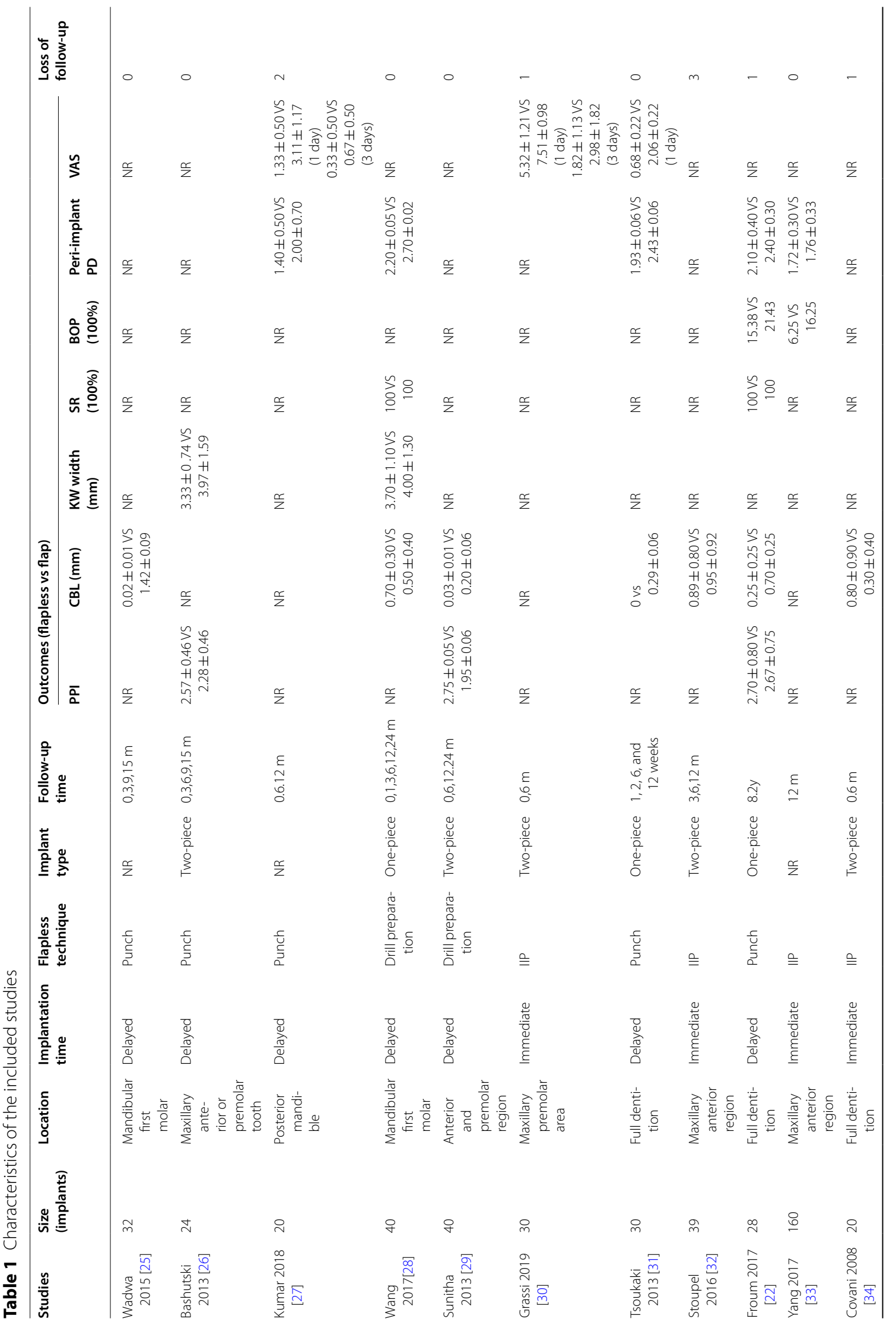




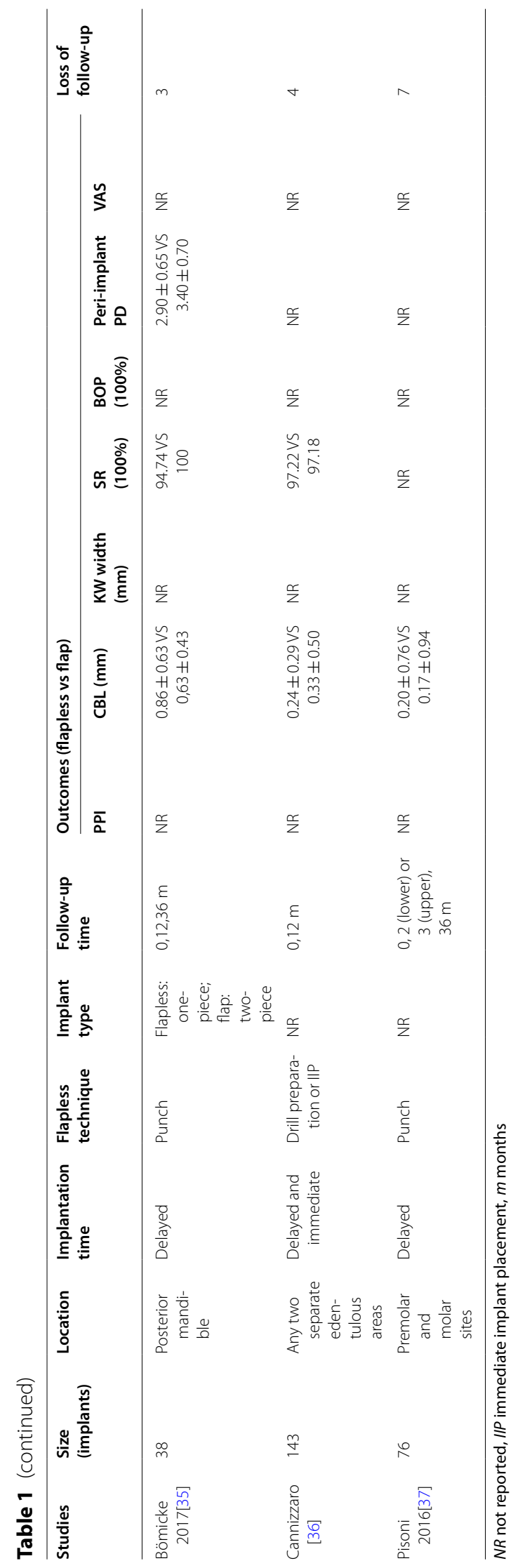




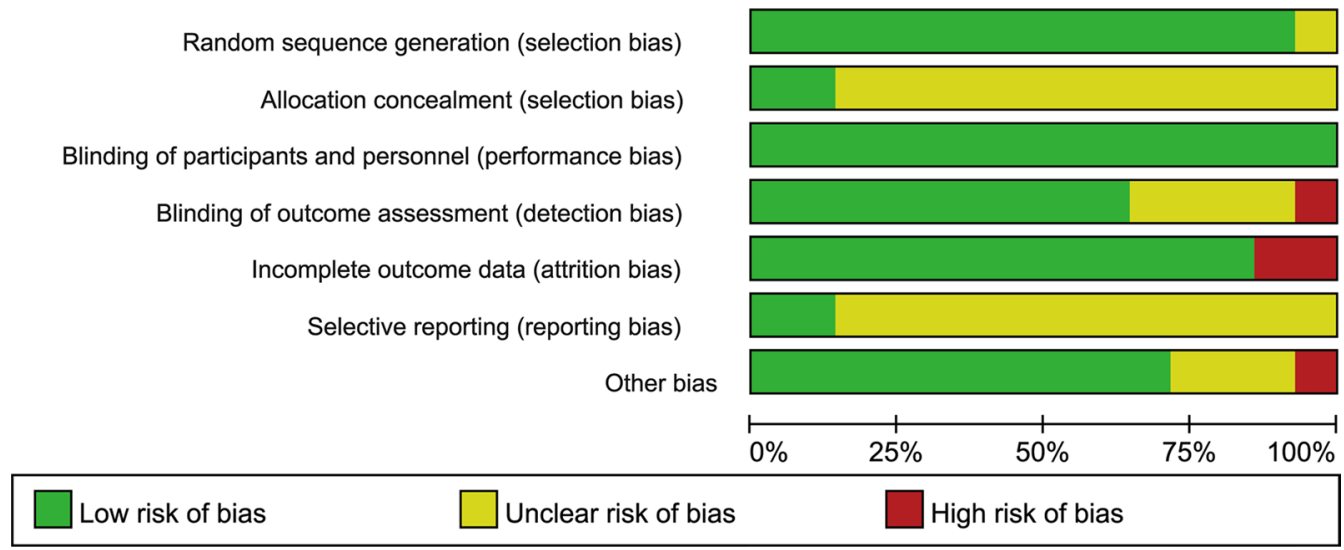

Fig. 2 Bias items presented as percentages across all included studies

presentation compared to the flap technique (flapless VS flap: $\mathrm{WMD}=0.32,95 \% \mathrm{CI}(0.28,0.35), P<0.001)$ (Fig. 5a).

KM width was further compared between 2 studies containing 64 implants. No significant difference was detected between the two procedures (flapless VS flap: $\mathrm{WMD}=-0.42,95 \%$ CI $(-1.02,0.17), P=0.160)$ (Fig. 5b).

The results of CBL were classified into two subgroups: immediate implantation and delayed implantation. Either the immediate subgroup (flapless VS flap: $\mathrm{WMD}=0.14$, 95\% CI $(-0.16,0.44), P=0.360)$ or the delayed implant subgroup (flapless VS flap: WMD $=-0.24,95 \%$ CI $(-0.84,0.36), P=0.430)$ would lead to insignificant differences in CBL. As can be seen in Fig. 5c, there was no significant difference in crestal bone changes between two groups overall (flapless VS flap: WMD $=-0.13,95 \%$ CI $(-0.63,0.38), P=0.630)$.

\section{Risk of bias across studies}

The publication bias was estimated via Egger's test. No significant publication bias were detected among the studies in these analyses (flapless VS flap: SR: coefficient $=-0.074,95 \% \mathrm{CI}(-0.487,0.340), P=0.523$; periimplant PD: coefficient $=2.202,95 \% \mathrm{CI}(-4.245,8.650)$, $P=0.397$; VAS: coefficient $=-1.811,95 \%$ CI $(-10.462$, 6.841), $P=0.229$; PPI: coefficient $=-0.620,95 \% \mathrm{CI}$ $(-6.070,4.830), P=0.385$; CBL: coefficient $=3.435,95 \%$ CI $(-11.831,18.701), P=0.618)$. The results of BOP and $\mathrm{KM}$ width were not evaluated by publication bias due to the limited number of included studies $(n=2)$.

\section{Additional analysis}

Sensitivity analyses were then conducted. The results of SR and peri-implant PD meta-analysis were not affected when any included study was omitted (Fig. 6a, b). The $95 \% \mathrm{CI}$ of the data in one study comparing PPI was not within the upper and lower limits, while the exclusion of this data did not affect the final results (Fig. 6c). This also indicated a great deal of certainty.

Subgroups analyses of VAS scores and CBL were also conducted and the results were clarified above.

\section{Discussion}

This meta-analysis included 14 RCTs analyzing clinical performances of 720 implants over a follow-up of 3 months or more. Quality of the included studies was generally low. Based on the results of analyses, the flapless technique showed better effects on the gingival papillae preservation, induced less peri-implant probing depth, and brought less pain and discomfort, compared with the flap technique. However, flapless and flap techniques showed comparable effects over SR, BOP, KM width, and CBL.

Flapless and flap procedures are both widely applied in implanting [39]. As high survival rate is one basic requirement for dental implanting, we have compared SR of the two approaches and found no significant difference, which was consistent with previously published reviews [9-11]. In most of the included studies, patients were prescreened using radiographs to make sure that there was enough bone volume for implantation. In that case, SR would be guaranteed in both groups.

The incidence of peri-implantitis was then evaluated by BOP [40]. The overall BOP of the two groups were both low and the between-group difference were insignificant. The follow-up time of the two included studies were 1 year and 8.2 years, respectively, indicating that neither flapless nor flap technique may show side effect on periimplant tissues in the long term.

After implant surgery and mucosa injury, there is about 6-8 weeks of wound healing and maturation [41]. This meta-analysis only included studies comparing the 


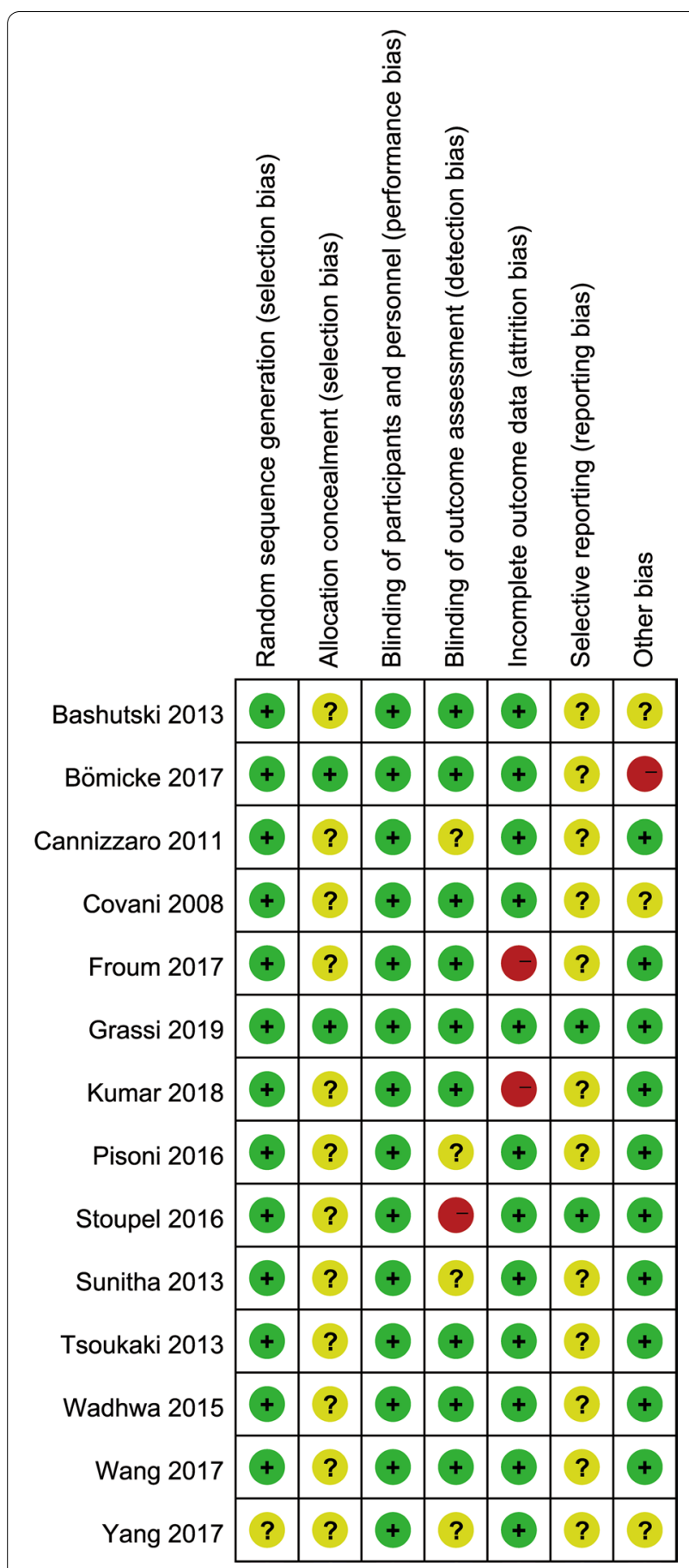

Fig. 3 Risk of bias summary: each risk of bias item for each included study

peri-implant depth over 3 months, which is long enough for the full recovering of gingival mucosa. The soft tissue seal around implants was essential as it makes a barrier for the invasive bacteria and other foreign microbes. However, an overlong soft tissue length around implants (peri-implant $\mathrm{PD}>5 \mathrm{~mm}$ ) indicates the high risks of peri-implantitis [42]. In all of the studies, the mean PD was within $4 \mathrm{~mm}$, which indicated no significant risks of peri-implantitis. As can be seen in Fig. 3c, when the gingiva was fully recovered, PD in flapless group was deeper than the flap one. This was in accordance with an in vivo canine study, which reported a $0.7-\mathrm{mm}$ deeper probing depth after flap implantation compared with the flapless technique [43]. The increased PD may be due to the severer inflammatory infiltration and fibroplasia around incisions in the flap group.

VAS is considered as a valid tool for assessing dental perception [44]. Within the first day after surgery, the VAS was the highest but still within the acceptable range of pain scales for the two approaches. Within 1-3 days after surgery, the mean VAS was below 1 in both the two groups. Patients would experience less pain and discomfort in the flapless approach in the first day. However, flapless and flap approaches resulted in comparable pain and discomfort 3 days later. Therefore, the flapless technique is a minimally invasive approach and could offer patients a better surgery experience.

The degree of gingival presentation is regarded as an important aspect of aesthetic effect after implantation and graded as a component in the "pink aesthetic scores" $[45,46]$. PPI was measured only in three studies that compared the delayed implant surgeries and only two of them compared it in the aesthetic regions. The flapless approach has led more gingival papillae presentation compared with the flap one and the difference was quite significant. The vertical distance from the alveolar crest to contact area of two adjacent crowns is considered as the most significant factor for gingival papillae presentation [47]. When the distance was lower or equal to $5 \mathrm{~mm}$, the papillae was presented in $98 \%$ of the ceases. With the vertical distance rising, PPI continuously reduced [48, 49]. In the delayed implant procedures, the flap technique would involve a horizontal incision between the adjacent teeth, the operation and the tension in suture may impair the recovering of gingival papillae. Besides, elevating mucosa flaps would cut the blood supply from the periosteal and mucosa and thus may cause the interdental alveolar crest absorption.

Keratinized mucosa is essential for the health and aesthetics of peri-implant tissue in anterior regions. When only 3-4 mm keratinized mucosa was presented on the buccal side of the gingival, a lateral flap advancement was indicated for further surgery. Sites with $\mathrm{KM}$ width $<2 \mathrm{~mm}$ showed a higher chances of suppuration and marginal bone loss [50]. Nonetheless, chances are really high that the patients have gummy smile issues when an excessive $\mathrm{KM}$ width is presented in the maxillary anterior region [51]. Flapless techniques for delayed implant placement 


\section{(a)}

\begin{tabular}{|c|c|c|c|c|c|c|c|}
\hline Study or Subgroup & $\begin{array}{l}\text { Flaple } \\
\text { Events }\end{array}$ & $\begin{array}{l}\text { ss } \\
\text { Total }\end{array}$ & $\begin{array}{l}\text { Flap } \\
\text { Events }\end{array}$ & Total & Weight & $\begin{array}{l}\text { Risk Difference } \\
\text { M-H, Fixed, } 95 \% \mathrm{Cl}\end{array}$ & $\begin{array}{c}\text { Risk Difference } \\
\text { M-H, Fixed, } 95 \% \mathrm{Cl}\end{array}$ \\
\hline Bömicke 2017 & 18 & 19 & 16 & 16 & $14.2 \%$ & $-0.05[-0.19,0.09]$ & \\
\hline Cannizzaro 2011 & 70 & 72 & 69 & 71 & $58.4 \%$ & $0.00[-0.05,0.05]$ & \\
\hline Froum 2017 & 13 & 13 & 14 & 14 & $11.0 \%$ & $0.00[-0.13,0.13]$ & \\
\hline Wang 2017 & 20 & 20 & 20 & 20 & $16.3 \%$ & $0.00[-0.09,0.09]$ & \\
\hline Total $(95 \% \mathrm{Cl})$ & & 124 & & 121 & $100.0 \%$ & $-0.01[-0.05,0.04]$ & \\
\hline Total events & 121 & & 119 & & & & \\
\hline $\begin{array}{l}\text { Heterogeneity: } \mathrm{Chi}^{2}= \\
\text { Test for overall effect }\end{array}$ & $\begin{array}{l}51, \mathrm{df}=3 \\
=0.32\end{array}$ & $\begin{array}{l}3(P=C \\
P=0.7\end{array}$ & $\begin{array}{l}0.92) ; 1^{2}= \\
\text { 5) }\end{array}$ & $0 \%$ & & & 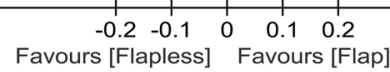 \\
\hline
\end{tabular}

(b)

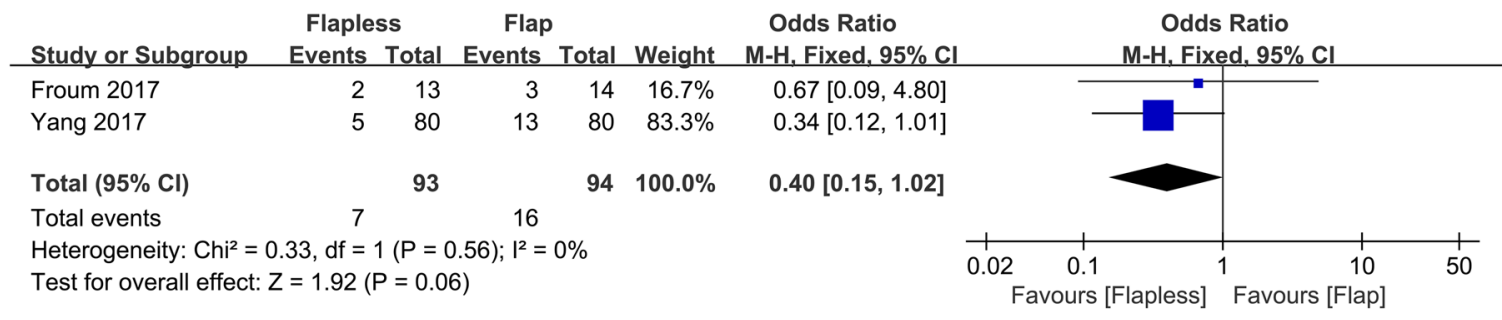

(c)

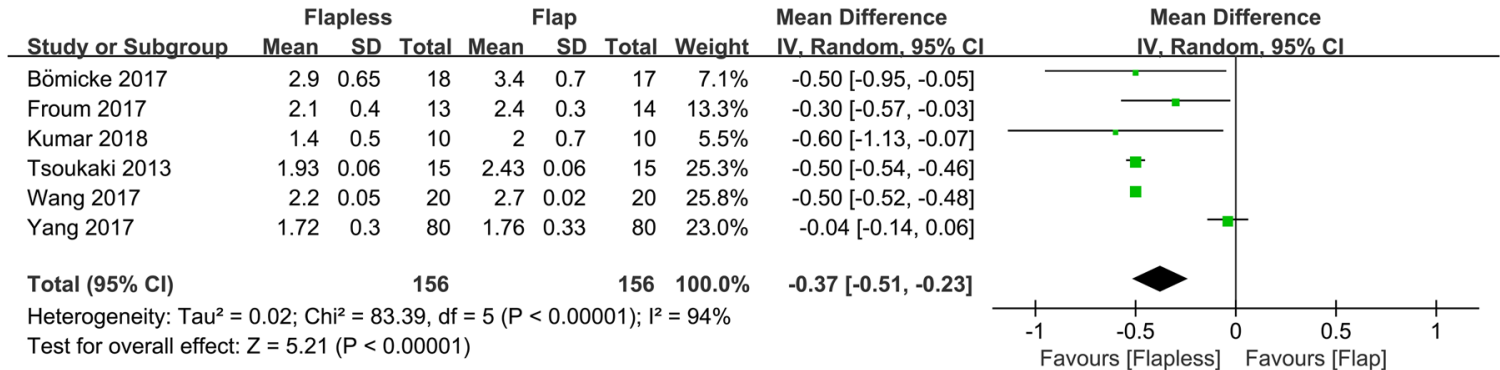

(d)

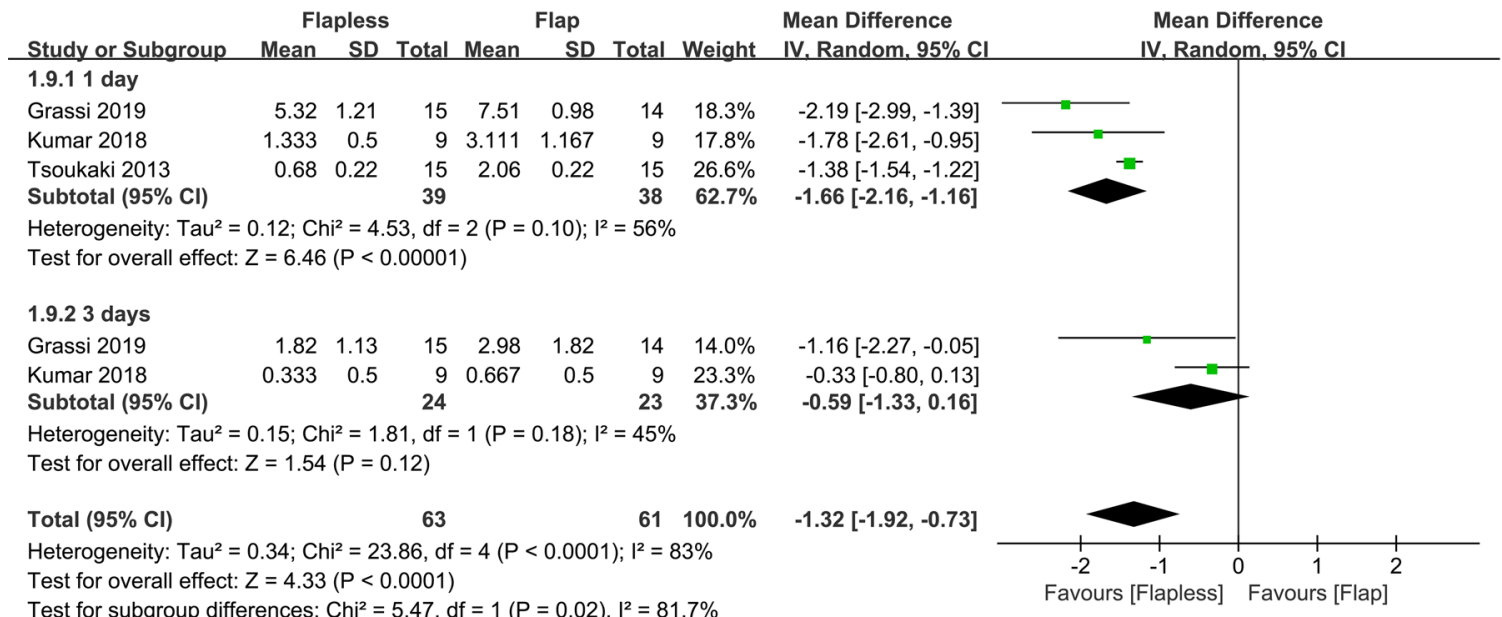

Fig. 4 Comparisons of general outcomes after flapless and flap techniques. a SR, b BOP, $\mathbf{c}$ peri-implant PD, $\mathbf{d} V A S$ 
(a)

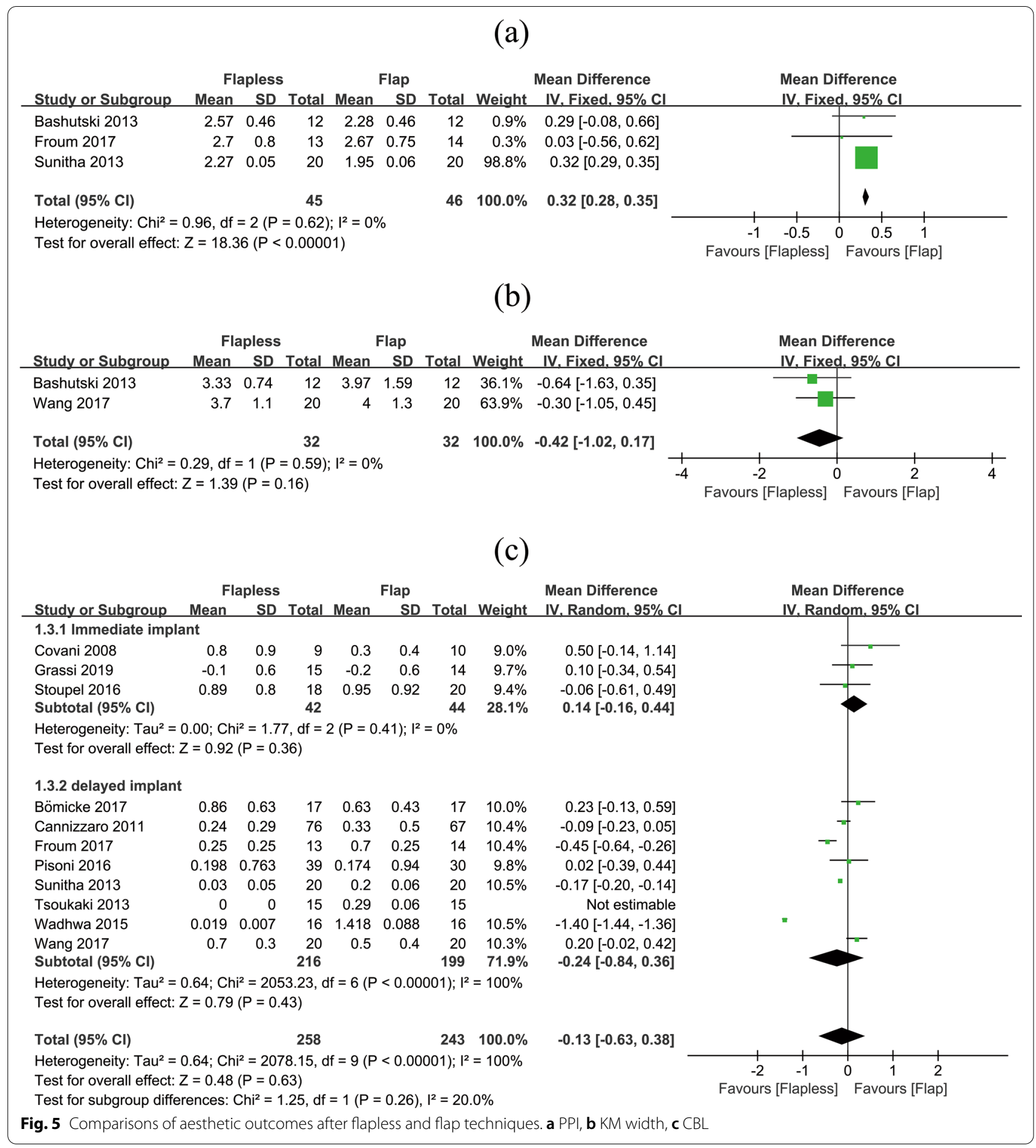

require a circumferential excision of keratinized mucosa at the implant site. Even though a part of the keratinized mucosa was excised in the flapless group, no significant decrease in KM width was detected.

CBL was detected for diagnosing peri-implantitis and evaluating the aesthetic effects. Greater CBL might indicate the subsequent marginal recession in the long term and increasing aesthetic risks. Most of the selected studies measured the CBL by radiographic images. However, some included the immediate implant treatments and some included delayed implant treatments. As the implant timing would influence CBL and there was 


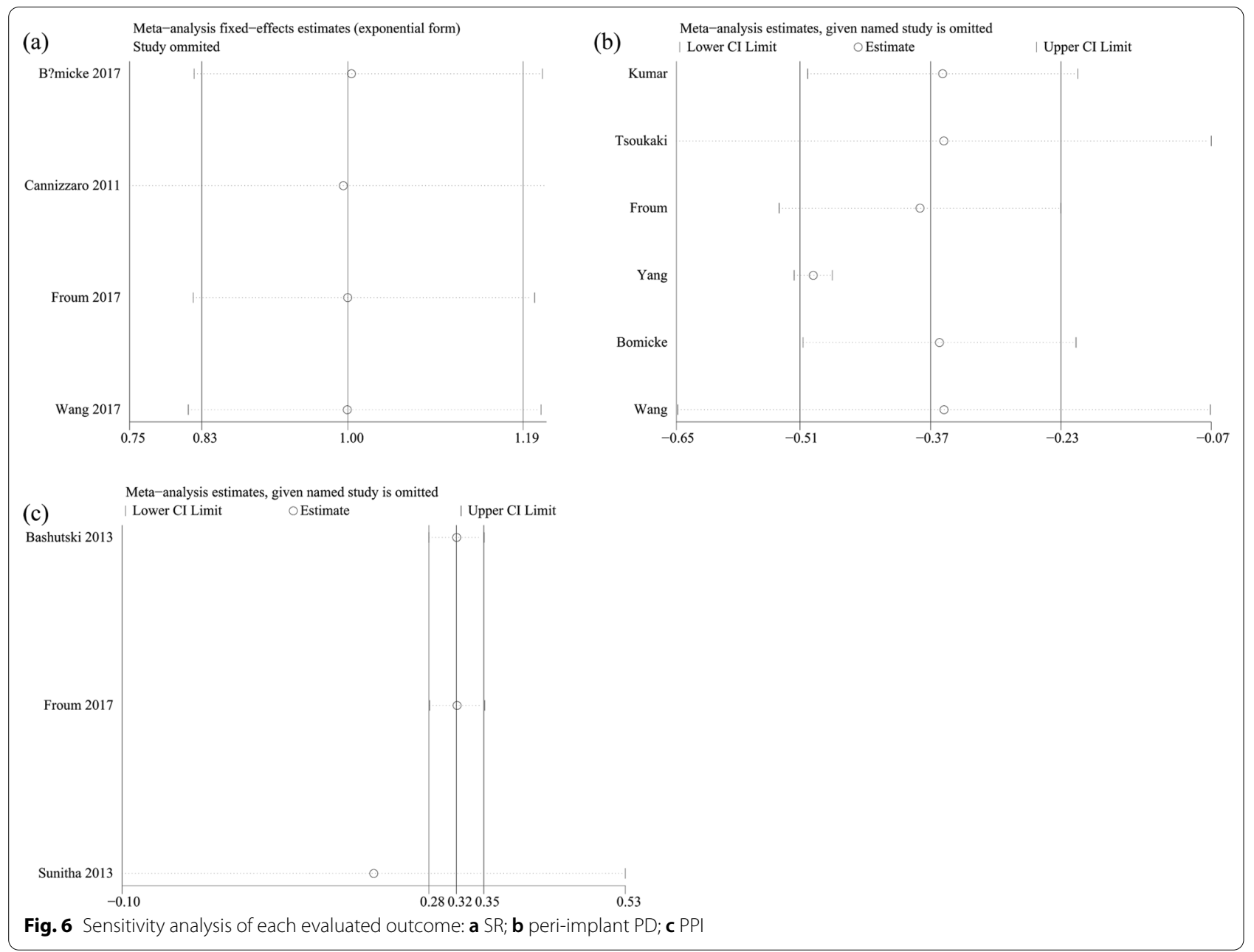

analysis indicating that immediate implant placement would result in more marginal bone loss, we conducted subgroup analysis [52]. However, in the two subgroups, the difference of CBL was not significant. A previous study has demonstrated that the partial-thickness flaps would lead to regenerated bone in 3-7 days, while full-thickness flaps lead to no bone regeneration [53]. Although most of the included studies have not stated whether the partial-thickness or full-thickness flaps was applied in their studies, no difference of marginal bone height was detected.

This was the first systematic review and meta-analysis of only RCTs to assess both the general and aesthetic outcomes between flapless and flap implant techniques. We included only RCTs to increase the robustness of the results. Aesthetic effects were compared for the first time in the review. However, there were some shortcomings in the analysis. Flapless techniques, including punch, drill preparation and IIP, were all included in our study to get a comprehensive summary of the effects of flapless technique. The geometry and biological situations of the soft and hard tissues between the IIP and punch procedures might be different. Nonetheless, we conducted subgroup analyses between immediate and delayed (punch/drilling) flapless procedures and flapped procedures in our study when the number of included studies in each subgroup was sufficient $(n \geq 2)$. Also, more sensitivity analyses have been applied and the exclusion of the studies that used immediate or delayed implant placement did not affect the final results. Few studies compared the aesthetic effects of the two groups. Even when the aesthetic outcomes were taken into consideration in some trials, there are no sufficient data to thoroughly elucidate the outcomes. More thorough investigations are needed to compare the aesthetic effects, such as soft tissue contour around implants, soft tissue level and alveolar process deficiency. 


\section{Conclusions}

This meta-analysis revealed that flapless techniques could help to preserve gingival papillae and reduce the pain and discomfort after surgeries. Besides, the flapless procedure showed less peri-implant probing depth. Flapless technique would be recommended in implanting when there is enough soft and hard tissue dimension. More highquality and aesthetics-related RCTs are needed to draw a more comprehensive conclusion.

\begin{abstract}
Abbreviations
RCTs: Randomized controlled trials; SR: Survival rate; BOP: Bleeding on probing; PD: Probing depth; VAS: Visual analogue scale; PPI: Papillae presentation index; KM: Keratinized mucosa; CBL: Crestal bone loss; RR: Risk ratio; OR: Odd ratio; $\mathrm{Cl}$ : Confidence interval; WMD: Weighted mean differences; PRISMA: Systematic Reviews and Meta-analyses; PICOS: Participants-Interventions-ComparisonsOutcomes-Study Design; IIP: Immediate implant placement; NR: Not reported.
\end{abstract}

\section{Acknowledgements}

Not applicable

\section{Authors' contributions}

$X G$ and $S Q$ researched and graded the researches. XG prepared manuscript and $\mathrm{HC}$ revised the manuscript. XG and QW designed the study. $\mathrm{HC}$ and QW were the supervisors of the research. All authors read and approved the final manuscript.

\section{Funding}

This research was financed by Key research program of Sichuan Science and technology Department (Grant No. 21ZDYF1797).

\section{Availability of data and materials}

Not applicable.

\section{Declarations}

Ethics approval and consent to participate Not applicable.

\section{Consent for publication}

Not applicable.

\section{Competing interests}

The authors declare that they have no conflict of interest.

Received: 28 April 2021 Accepted: 9 August 2021

Published online: 01 October 2021

\section{References}

1. Jung RE, Zembic A, Pjetursson BE, Zwahlen M, Thoma DS. Systematic review of the survival rate and the incidence of biological, technical, and aesthetic complications of single crowns on implants reported in longitudinal studies with a mean follow-up of 5 years. Clin Oral Implant Res. 2012;23(Suppl 6):2-21.

2. Pjetursson BE, Thoma $D$, Jung $R$, Zwahlen $M$, Zembic A. A systematic review of the survival and complication rates of implant-supported fixed dental prostheses (FDPs) after a mean observation period of at least 5 years. Clin Oral Implant Res. 2012;23(Suppl 6):22-38.

3. Romeo E, Storelli S. Systematic review of the survival rate and the biological, technical, and aesthetic complications of fixed dental prostheses with cantilevers on implants reported in longitudinal studies with a mean of 5 years follow-up. Clin Oral Implant Res. 2012;23(Suppl 6):39-49.
4. Hutchens LH, Beauchamp SD, McLeod SH, Stern JK. Considerations for Incision and Flap Design With Implant Therapy in the Esthetic Zone. Implant Dent. 2018;27(3):381-7.

5. Campelo L, Camara J. Flapless implant surgery: a 10-year clinical retrospective analysis. Int J Oral Maxillofac Implants. 2002;17(2):271-6.

6. Sclar AG. Guidelines for flapless surgery. J Oral Maxillofac Surg . 2007;65(7 Suppl 1):20-32.

7. Jeong SM, Choi BH, Li J, Kim HS, Ko CY, Jung JH, et al. Flapless implant surgery: an experimental study. Oral Surg, Oral Med, Oral Pathol, Oral Radiology, Endod. 2007;104(1):24-8.

8. Sclar A. Guidelines for flapless surgery. J Oral Maxillofac Surg . 2007:65:20-32.

9. Cai H, Liang $X$, Sun DY, Chen JY. Long-term clinical performance of flapless implant surgery compared to the conventional approach with flap elevation: A systematic review and meta-analysis. World J Clin Cases. 2020;8(6):1087-103.

10. Lin GH, Chan HL, Bashutski JD, Oh TJ, Wang HL. The effect of flapless surgery on implant survival and marginal bone level: a systematic review and meta-analysis. J Periodontol. 2014;85(5):e91-103.

11. Lemos CAA, Verri FR, Cruz RS, Gomes JML, Dos Santos DM, Goiato MC, et al. Comparison between flapless and open-flap implant placement: a systematic review and meta-analysis. Int J Oral Maxillofac Surg. 2020. https://doi.org/10.1016/j.ijom.2018.04.002.

12. Zhuang J, Zhao D, Wu Y, Xu C. Evaluation of outcomes of dental implants inserted by flapless or flapped procedure: a meta-analysis. Implant Dent. 2018;27(5):588-98.

13. Lee J, Lee JB, Koo KT, Seol YJ, Lee YM. Flap management in alveolar ridge preservation: a systematic review and meta-analysis. Int J Oral Maxillofac Implants. 2018;33(3):613-21.

14. Gobbato L, Avila-Ortiz G, Sohrabi K, Wang CW, Karimbux N. The effect of keratinized mucosa width on peri-implant health: a systematic review. Int J Oral Maxillofac Implants. 2013;28(6):1536-45.

15. Frisch E, Ziebolz D, Vach K, Ratka-Krüger P. The effect of keratinized mucosa width on peri-implant outcome under supportive postimplant therapy. Clin Implant Dent Relat Res. 2015;17(Suppl 1):e236-44.

16. Moher D, Liberati A, Tetzlaff J, Altman DG. Preferred reporting items for systematic reviews and meta-analyses: the PRISMA statement. J Clin Epidemiol. 2009;62(10):1006-12.

17. Buser D, Janner SFM, Wittneben J-G, Braegger U, Ramseier CA, Salvi GE. 10-year survival and success rates of 511 titanium implants with a sandblasted and acid-etched surface: a retrospective study in 303 partially edentulous patients. Clin Implant Dent Relat Res. 2012;14(6):839-51.

18. Monje A, Blasi G. Significance of keratinized mucosa/gingiva on periimplant and adjacent periodontal conditions in erratic maintenance compliers. J Periodontol. 2019;90(5):445-53.

19. Daubert D, Weinstein B, Bordin S, Leroux B, Flemming T. Prevalence and predictive factors for peri-implant disease and implant failure: a crosssectional analysis. J Periodontol. 2015;86(3):337-47.

20. Papi P, Penna D, Di Murro B, Pompa G. Clinical and volumetric analysis of peri-implant soft tissue augmentation using an acellular dermal matrix: A prospective cohort study. J Periodontol. 2020. https://doi.org/ 10.1002/JPER.20-0219.

21. Ravida A, Galli M, Siqueira R, Saleh MHA, Galindo-Morenzo P, Wang HL. Diagnosis of peri-implant status after peri-implantitis surgical treatment: Proposal of a new classification. J Periodontol. 2020. https://doi. org/10.1002/JPER.20-0124.

22. Eli I, Baht R, Kozlovsky A, Simon $\mathrm{H}$. Effect of gender on acute pain prediction and memory in periodontal surgery. Eur J Oral Sci. 2000;108(2):99-103.

23. Froum SJ, Khouly I. Survival rates and bone and soft tissue level changes around one-piece dental implants placed with a flapless or flap protocol: 8.5-year results. Int J Periodontics Restorative Dent. 2017:37(3):327-37.

24. Lin GH, Chan HL, Wang HL. The significance of keratinized mucosa on implant health: a systematic review. J Periodontol. 2013;84(12):1755-67.

25. Egger M, Davey Smith G, Schneider M, Minder C. Bias in meta-analysis detected by a simple, graphical test. BMJ. 1997;315(7109):629-34.

26. Wadhwa B, Jain V, Bhutia O, Bhalla AS, Pruthi G. Flapless versus open flap techniques of implant placement: a 15-month follow-up study. Indian J Dental Res. 2015;26(4):372-7. 
27. Bashutski JD, Wang HL, Rudek I, Moreno I, Koticha T, Oh TJ. Effect of flapless surgery on single-tooth implants in the esthetic zone: a randomized clinical trial. J Periodontol. 2013;84(12):1747-54.

28. Kumar D, Sivaram G, Shivakumar B, Kumar T. Comparative evaluation of soft and hard tissue changes following endosseous implant placement using flap and flapless techniques in the posterior edentulous areas of the mandible-a randomized controlled trial. Oral Maxillofac Surg. 2018;22(2):215-23.

29. Wang F, Huang W, Zhang ZY, Wang HW, Monje A, Wu YQ. Minimally invasive flapless vs flapped approach for single implant placement: a 2-year randomized controlled clinical trial. Clin Oral Implant Res. 2017;28(6):757-64.

30. Sunitha RV, Sapthagiri E. Flapless implant surgery: a 2-year followup study of 40 implants. Oral Surg Oral Med Oral Pathol Oral Radiol. 2013;116(4):e237-43.

31. Grassi FR, Grassi R, Rapone B, Alemanno G, Balena A, Kalemaj Z. Dimensional changes of buccal bone plate in immediate implants inserted through open flap, open flap and bone grafting and flapless techniques: a cone-beam computed tomography randomized controlled clinical trial. Clin Oral Implant Res. 2019;30(12):1155-64.

32. Tsoukaki M, Kalpidis CD, Sakellari D, Tsalikis L, Mikrogiorgis G, Konstantinidis A. Clinical, radiographic, microbiological, and immunological outcomes of flapped vs. flapless dental implants: a prospective randomized controlled clinical trial. Clin Oral Implant Res. 2013;24(9):969-76.

33. Stoupel J, Lee CT, Glick J, Sanz-Miralles E, Chiuzan C, Papapanou PN. Immediate implant placement and provisionalization in the aesthetic zone using a flapless or a flap-involving approach: a randomized controlled trial. J Clin Periodontol. 2016;43(12):1171-9.

34. Yang $L, L u W Q$. The effect and safety of two techniques of immediate implants on alveolar bone length, soft and hard tissue in the anterior maxillary zone. Shanghai J Stomatol. 2017;26(3):317-20.

35. Covani U, Cornelini R, Barone A. Buccal bone augmentation around immediate implants with and without flap elevation: a modified approach. Int J Oral Maxillofac Implants. 2008;23(5):841-6.

36. Bömicke W, Gabbert O, Koob A, Krisam J, Rammelsberg P. Comparison of immediately loaded flapless-placed one-piece implants and flappedplaced conventionally loaded two-piece implants, both fitted with all-ceramic single crowns, in the posterior mandible: 3-year results from a randomised controlled pilot trial. Eur J Oral Implantol. 2017;10(2):179-95.

37. Cannizzaro G, Felice P, Leone M, Checchi V, Esposito M. Flapless versus open flap implant surgery in partially edentulous patients subjected to immediate loading: 1-year results from a split-mouth randomised controlled trial. Eur J Oral Implantol. 2011;4(3):177-88.

38. Pisoni L, Ordesi P, Siervo P, Bianchi AE, Persia M, Siervo S. Flapless versus traditional dental implant surgery: long-term evaluation of crestal bone resorption. J Oral Maxillofac Surg. 2016;74(7):1354-9.

39. Blanco J, Carral C, Argibay O, Liñares A. Implant placement in fresh extraction sockets. Periodontol. 2019;79(1):151-67.
40. Hashim D, Cionca N, Combescure C, Mombelli A. The diagnosis of periimplantitis: a systematic review on the predictive value of bleeding on probing. Clin Oral Implant Res. 2018. https://doi.org/10.1111/clr.13127.

41. Berglundh T, Abrahamsson I, Welander M, Lang NP, Lindhe J. Morphogenesis of the peri-implant mucosa: an experimental study in dogs. Clin Oral Implant Res. 2007;18(1):1-8.

42. Heitz-Mayfield LJA, Heitz F, Lang NP. Implant Disease Risk Assessment IDRA-a tool for preventing peri-implant disease. Clin Oral Implant Res. 2020;31(4):397-403.

43. You TM, Choi BH, Li J, Xuan F, Jeong SM, Jang SO. Morphogenesis of the peri-implant mucosa: a comparison between flap and flapless procedures in the canine mandible. Oral surg, Oral Med, Oral Pathol, Oral Radiol, Endod. 2009;107(1):66-S0.

44. Seymour RA, Charlton JE, Phillips ME. An evaluation of dental pain using visual analogue scales and the Mcgill Pain Questionnaire. J Oral Maxillofacial Surg . 1983;41(10):643-8.

45. Jemt T. Regeneration of gingival papillae after single-implant treatment. Int J Periodontics Restorative Dent. 1997;17(4):326-33.

46. Cosyn J, Thoma D, Hämmerle C, De Bruyn H. Esthetic assessments in implant dentistry: objective and subjective criteria for clinicians and patients. Periodontol. 2017;73(1):193-202.

47. Tarnow D, Magner A, Fletcher P. The effect of the distance from the contact point to the crest of bone on the presence or absence of the interproximal dental papilla. J Periodontol. 1992;63(12):995-6.

48. Tarnow D, Elian N, Fletcher P, Froum S, Magner A, Cho S, et al. Vertical distance from the crest of bone to the height of the interproximal papilla between adjacent implants. J Periodontol. 2003;74(12):1785-8.

49. Roccuzzo M, Roccuzzo A, Ramanuskaite A. Papilla height in relation to the distance between bone crest and interproximal contact point at singletooth implants: a systematic review. Clin Oral Implants Res. 2018. https:// doi.org/10.1111/clr.13116.

50. Ravidà A, Saleh I, Siqueira R, Garaicoa-Pazmiño C, Saleh M, Monje A, et al. Influence of keratinized mucosa on the surgical therapeutical outcomes of peri-implantitis. J Clin Periodontol. 2020;47(4):529-39.

51. Zardawi F, Gul S, Fatih M, Hama B. Surgical procedures reducing excessive gingival display in gummy smile patients with various etiologic backgrounds. Clin Adv Periodontics. 2020;10(3):130-4.

52. Bassir S, El Kholy K, Chen C, Lee K, Intini G. Outcome of early dental implant placement versus other dental implant placement protocols: a systematic review and meta-analysis. J Periodontol. 2019;90(5):493-506.

53. Valderrama P, Oates T, Jones A, Simpson J, Schoolfield J, Cochran D. Evaluation of two different resonance frequency devices to detect implant stability: a clinical trial. J Periodontol. 2007;78(2):262-72.

\section{Publisher's Note}

Springer Nature remains neutral with regard to jurisdictional claims in published maps and institutional affiliations.

\section{Submit your manuscript to a SpringerOpen ${ }^{\odot}$ journal and benefit from:}

- Convenient online submission

- Rigorous peer review

- Open access: articles freely available online

- High visibility within the field

Retaining the copyright to your article

Submit your next manuscript at springeropen.com 